\title{
Neuropsychological syndromes in presenile dementia due to cerebral atrophy
}

\author{
D NEARY, JS SNOWDEN, DM BOWEN, $\dagger$ NR SIMS, $\dagger$ DMA MANN, ${ }^{*}$ JS BENTON, $\dagger$ \\ B NORTHEN, PO YATES, ${ }^{*}$ AN DAVISON $\dagger$
}

From the Department of Neurology, Manchester Royal Infirmary, Department of Neuropathology, University of Manchester* and the Department of Neurochemistry, $\dagger$ Institute of Neurology, London, UK

SUMMARY In a prospective study of 24 patients with presenile dementia associated with cerebral atrophy, clinical and psychological characteristics of patients' disorder were examined in relation to pathological and chemical findings obtained from tissue analysis following cerebral biopsy. The histological features of Alzheimer's disease were found in $75 \%$ of cases, but not in $25 \%$. Distinctive patterns of neuropsychological breakdown emerged allowing clinical grouping of patients. While clinical patterns were helpful in differentiating Alzheimer's disease from non-Alzheimer's disease, there was not an absolute concordance between clinical and patho-chemical groupings. The findings, which support the notion that the "cerebral atrophies" represent a heterogeneous group of conditions, have relevance for the clinical diagnosis of presenile dementia.

Dementia occurring in the presenium may have a variety of causes, which include progressive intrinsic cerebral disease, neurosurgically treatable conditions and metabolic disorders. Many of the patients referred to a neurological centre fall into the first category, and when readily identifiable conditions such as Huntington's Chorea have been excluded there remains a substantial proportion of the dementing population subsumed under the general category of "cerebral atrophy of unknown cause".' It is frequently suspected that most of these patients will have Alzheimer's disease, and a small minority Pick's disease. Precise clinical diagnosis is however sufficiently uncertain that such nomenclature as "degenerative dementia of the Alzheimer type", or "Alzheimer-like disease" has been adopted where histological confirmation of disease is unavailable. Such diagnostic uncertainty is reinforced by recent cortical biopsy studies of patients with cerebral atrophy. ${ }^{2-4}$ Although cerebral senile plaques and neurofibrillary tangles characteristic of Alzheimer's disease were seen in the largest proportion of patients a significant minority showed no specific histological features and a definitive diagnosis of

\footnotetext{
Address for reprint requests: Dr D Neary, Department of Neurology, Manchester Royal Infirmary, Manchester M13 9WL, UK.
}

Received 11 December 1984 and in revised form 22 June 1985. Accepted 27 June 1985
Pick's disease could be made only rarely. Moreover, Alzheimer's disease could not invariably be distinguished from non-Alzheimer's disease on the basis of clinical features. ${ }^{3}$ It could be argued that the absence of pathological findings simply reflects a relative sparing of the part of the brain sampled at cerebral biopsy, and that positive Alzheimer's disease pathology would have been demonstrated had a different site been sampled. ${ }^{2}$ Alternatively, cerebral atrophy may represent a more heterogeneous group of disorders than is often suspected. The failure to draw clear clinical distinctions between patients may reflect inadequate or insensitive neuropsychological analysis, or else may indicate that cerebral atrophy, including Alzheimer's disease, is not associated with distinctive neuropsychological syndromes.

The importance of accurate classification of this common group of disorders is self-evident but is reinforced by the emergence of possible therapies for patients with Alzheimer's disease and the need to identify such individuals with confidence. Examination of clinical features of patients in whom pathological and chemical information is available provides a means of evaluating the precision of clinical diagnosis and of identifying possibly distinctive neuropsychological characteristics associated with a particular pathological and chemical disorder.

The present paper reports a prospective study of 24 patients, with a diagnosis of primary cerebral atrophy. Clinical investigations of patients included 
a qualitative mental assessment to identify profiles of cognitive performance. Clinical profiles were compared with findings from pathological and neurochemical analysis of tissue obtained from cerebral biopsy.

\section{Materials and methods}

\section{Subjects}

The study group consisted of 24 patients, 15 female and nine male, who conformed to the general clinical diagnosis of "cerebral atrophy of unknown cause".' The criteria for diagnosis of primary cerebral atrophy were: (a) a history of progressive deterioration in mental function of at least one year's duration, leading to a reduction in social and occupational capacity, (b) absence of cardiovascular and other systemic disease, and of a history of alcohol abuse and major head injury, (c) the presence of enlarged cerebral ventricles and cortical sulci and the absence of focal lesions on computed tomography.

At the time of investigation the patients' mean age was 58 years, range $43-69$, and the mean duration of symptoms was $3 \cdot 5$ years, range $1-8$ years. In all patients symptoms had begun in the presenium. These 24 patients were drawn from a larger series of 200 presenile patients with cerebral atrophy who have undergone clinical investigation. The present study group appears to be representative of the larger group in terms of age and sex distribution and clinical features.

\section{Mental assessment}

Qualitative A series of short tests were designed to provide qualitative information about different aspects of mental function, and was sufficiently easy to avoid floor level performance in patients with dementia and to present no difficulty to normal control subjects. The assessment procedure, unpaced and carried out by a single tester, was identical for all patients, with the exception that, to avoid distress to the patient, tasks were omitted if their accomplishment was clearly precluded by failure on earlier tasks. Tasks, summarised in table 1 , were grouped for convenience under five major headings; however, since failure may arise for multiple reasons interpretation of disability was based on analysis of quality of performance and not rigidly according to the task's allocated category. The emphasis on qualitative evaluation of deficits was made in an attempt to highlight possible differences in patterns of disability. Reliance on test scores alone may be unhelpful in distinguishing neuropsychological profiles in dementia. ${ }^{5}$

Quantitative For later correlative studies ${ }^{6}$ mental test performance was rated for severity of disability. Test results were examined independently by the tester (second author) and consultant neurologist (first author), and rated from 0-3 in terms of extent of impairment (absent, mild, moderate and severe) in each of the following major domains: language, perceptuo-spatial abilities and memory. An overall clinical rating of disability represented the cumulation of these three assessments. Inter-rater agreement was high (Spearman rank correlation coefficient $=$ 0.96). Additional measures of relative degree of impairment were provided by the Wechsler Adult Intelligence

\section{Table 1 Summary of mental testing}

(1) Language

Spontaneous speech: social conversation with the examiner.

Series speech: production of overlearnt sequences, such as the days of the week.

Comprehension: of word meaning and grammatical relations, interpretation of metaphor and proverb.

Repetition: digit span, repetition of spoken phrases and word lists.

Word finding: naming objects and body parts to confrontation and description.

Verbal fluency: production of words conforming to specified category.

Spelling: oral spelling of specified words and aural identification of spelt words.

Reading: reading aloud and comprehension of written material.

Writing: reproduction of letters, words and phrases to dictation, and composition of sentence to command.

Calculation: mental and written additions and subtractions.

(2) Perceptual-spatial

Identification: of objects, line drawings, famous faces and jigsaw figures.

Location: of objects and body parts, and points on a map, matching fingers on the two hands.

Integration: interpretation of complex pictorial scenes.

Visual tracking: tracking a dotted line.

(3) Praxis and visuo-constructional

Symbolic motor actions: use of gesture and pantomime.

Non-representational: copying hand configurations.

Motor sequences: production of motor rhythms, sequences of hand movements, and alternating taps.

Constructional: drawing to command and from copy, reproduction of block constructions, reproduction of matchstick figures.

(4) Memory

Verbal memory: immediate and delayed recall and recognition of name and address and short story.

Visual memory: reproduction of drawings from memory, recognition of pictures.

General knowledge: identification of contemporary and past celebrities.

(5) Regulation: planning and conceptual functions

Picture sequencing: ordering pictures to tell a story.

Block sorting: grouping blocks according to common features.

Scale (WAIS), Token test and a Continuous Reaction time task and are discussed elsewhere. ${ }^{\circ}$

\section{Neurological examination}

A routine neurological examination was carried out, and motor and sensory signs recorded.

\section{Electroencephalography}

Routine bipolar electroencephalograms were carried out on all patients.

\section{Cerebral biopsy}

The procedure was approved by the Manchester Central District Ethical Committee. Biopsy was undertaken under general anaesthesia, of approximately 100 minutes duration. Tissue was dissected from the non-dominant (right) middle temporal gyrus in 20 cases, and from right frontal cortex in four patients. The approximate weight of tissue removed was $1 \mathrm{~g}$ for frontal biopsy and $1.25 \mathrm{~g}$ for temporal biopsy. Samples were divided for pathological and chemical analyses.

Pathological One third of the fresh biopsy tissue was immediately placed in $10 \%$ neutral formalin, fixed overnight and routinely processed. Paraffin blocks were cut in $5 \mu \mathrm{m}$ sections and stained by conventional techniques, including Gros-Bielchowsky silver staining. Measurements of frequency of senile plaques and cells bearing neurofibrit- 
Table 2 Summary of findings

\begin{tabular}{|c|c|c|c|c|c|c|}
\hline \multirow{2}{*}{$\begin{array}{l}\text { Patient } \\
\text { group }\end{array}$} & \multirow{2}{*}{$\begin{array}{l}\text { Neurological } \\
\text { signs }\end{array}$} & \multirow{2}{*}{$\begin{array}{l}\text { Psychological } \\
\text { disorder }\end{array}$} & \multirow{2}{*}{$\begin{array}{l}\text { EEG } \\
\text { abnormality }\end{array}$} & \multirow[t]{2}{*}{ Pathology } & \multicolumn{2}{|l|}{ Chemistry } \\
\hline & & & & & $\begin{array}{l}\text { Cerebral } A C h \\
\text { synthesis } C A T \\
\text { activity }\end{array}$ & $\begin{array}{l}\text { CSF HVA } \\
\text { reduction }\end{array}$ \\
\hline$A(n=11)$ & + & $\begin{array}{l}\text { amnesia p-sp } \\
\text { disorder aphasia }\end{array}$ & + & AD & reduced & none/moderate \\
\hline$B(n=3)$ & + & $\begin{array}{l}\text { amnesia p-sp } \\
\text { disorder }\end{array}$ & + & AD & reduced & none/moderate \\
\hline $\begin{array}{l}C(n=2) \\
D(n=2)\end{array}$ & $\begin{array}{l}+ \\
-\end{array}$ & $\begin{array}{l}\text { amnesia apraxia } \\
\text { amnesia }\end{array}$ & $\begin{array}{l}+ \\
+\end{array}$ & $\begin{array}{l}\mathrm{AD} \\
\mathrm{AD}\end{array}$ & $\begin{array}{l}\text { reduced } \\
\text { reduced }\end{array}$ & $\begin{array}{l}\text { none } \\
\text { none/moderate }\end{array}$ \\
\hline$E(n=4)$ & + & $\begin{array}{l}\text { conduct disorder } \\
\text { social change }\end{array}$ & - & non-specific & normal & none/moderate \\
\hline $\begin{array}{l}F(n=1) \\
G(n=1)\end{array}$ & + & $\begin{array}{l}\text { amnesia apraxia } \\
\text { amnesia p-sp } \\
\text { disorder aphasia }\end{array}$ & $\overline{+}$ & $\begin{array}{l}\text { non-specific } \\
\text { non-specific }\end{array}$ & $\begin{array}{l}\text { normal } \\
\text { normal }\end{array}$ & $\begin{array}{l}\text { severe } \\
\text { none }\end{array}$ \\
\hline
\end{tabular}

Symbols and abbreviations:

$\mathrm{ACh}=$ acetylcholine synthesis; $\mathrm{CAT}=$ choline acetyltransferase; $\mathrm{CSF}=$ cerebrospinal fluid; $\mathrm{HVA}=$ homovanillic acid.

+ denotes presence; - denotes absence (of neurological signs/EEG abnormality).

p-sp = perceptuo-spatial.

$\mathrm{AD}$ denotes presence of senile plaques and neurofibrillary tangles.

reduced denotes value significantly lower than controls.

$(\mathrm{n}=)=$ number of patients in designated group.

lary tangles were made on the Gros-Bielchowsky stained sections, using the method of Aherne and Diggle ${ }^{7}$ as detailed elsewhere. ${ }^{8}$ Control biopsy samples of apparently normal neocortex were obtained from the temporal lobes of five patients, mean age 42 , range $22-57$, during neurosurgical procedures.

Biochemical Neurosurgical samples were handled and processed for measuring $\mathrm{ACh}$ synthesis by incorporation of $\left(\mathrm{U}-{ }^{14} \mathrm{C}\right)$ glucose into $\left({ }^{14} \mathrm{C}\right) \mathrm{ACh}$ in neocortical tissue prisms, consisting mainly of synaptosomes, according to Sims et al..$^{9}$ Incubations were carried out in the presence of a high concentration of choline $(2 \mathrm{mM})$ and potassium ion $(31 \mathrm{mM})$. The CAT activity of cell free homogenates of neocortex was determined according to Fonnum. ${ }^{10}$ Prisms were prepared from $373 \pm 134 \mathrm{mg}$ (mean \pm SD) of neocortex while much less tissue $(47 \pm 31 \mathrm{mg})$ was homogenised for the determination of CAT activity. Control samples from patients aged 33-68 (mean 52 years) were taken from apparently normal neocortex of the temporal lobe during procedures for deep seated tumour removal. It has been shown that such samples provide a good indication of values for $\mathrm{ACh}$ synthesis and CAT activity of normal tissue, irrespective of the patient's age. ${ }^{911}$

The homovanillic acid content of lumbar CSF was determined either fluorometrically, ${ }^{12}$ or by high pressure liquid chromatography, using either a slight modification of the published method ${ }^{13}$ or that of Palmer et al..$^{14}$ The methods gave essentially identical values.

\section{Results}

Neuropsychological profiles demonstrated by patients, combined with the results of electroencephalography, pathological change in the cortex and chemical abnormalities in the brain and CSF distinguished seven patient groups, A-G (table 2).

Patients in groups $\mathrm{A}, \mathrm{B}, \mathrm{C}$ and $\mathrm{D}$ all had the pathological changes of Alzheimer's disease and a significant reduction in ACh synthesis and CAT activity in the cerebral cortex (table 3 ). The levels of HVA in the CSF were moderate, but significantly reduced relative to control values. ${ }^{14}$ Moreover, all patients had abnormal electroencephalograms, displaying a moderate non-specific increase in slow wave activity in the theta and delta range.

The six patients in groups $\mathrm{E}, \mathrm{F}$ and $\mathrm{G}$ did not have the patho-chemical changes of Alzheimer's disease, or indeed any specific morphological abnormality in

Table 3 Pathological and chemical values

\begin{tabular}{|c|c|c|c|c|c|c|}
\hline & & $\begin{array}{l}\text { Senile plaques } \\
\left(\mathrm{n} / \mathrm{mm}^{2}\right)\end{array}$ & $\begin{array}{l}\text { Neurofibrillary } \\
\text { tangles }\left(\mathrm{n} / \mathrm{mm}^{2}\right)\end{array}$ & $\begin{array}{l}\text { CAT activity } \\
\text { (nmol/min/mg) }\end{array}$ & $\begin{array}{l}\text { ACh synthesis } \\
(\mathrm{dpm} / \mathrm{min} / \mathrm{mg})\end{array}$ & $H V A(n g / m l)$ \\
\hline $\begin{array}{l}\text { Alzheimer's disease } \\
\text { Non-Alzheimer's } \\
\text { disease } \\
\text { Control }\end{array}$ & $\begin{array}{l}\text { Mean } \pm S D \\
\text { Range } \\
\text { Mean } \pm S D \\
\text { Range } \\
\text { Mean } \pm S D \\
\text { Range }\end{array}$ & $\begin{array}{l}20 \cdot 1 \pm 13.4(18) \ddagger \\
2 \cdot 6-51 \cdot 4 \\
0 \\
0\end{array}$ & $\begin{array}{l}25 \cdot 5 \pm 13 \cdot 2(18) \ddagger \\
0 \cdot 2-54 \cdot 2 \\
0 \\
0\end{array}$ & $\begin{array}{l}3 \cdot 0 \pm 1 \cdot 5(12) \ddagger \\
0 \cdot 9-4 \cdot 8 \\
11 \cdot 5 \pm 5 \cdot 0(5) \\
7 \cdot 4-19 \cdot 1 \\
8 \cdot 2 \pm 2 \cdot 4(7) \\
5 \cdot 4-12 \cdot 6\end{array}$ & $\begin{array}{l}2 \cdot 8 \pm 1 \cdot 0(17) \ddagger \\
1 \cdot 3-4 \cdot 6 \\
4 \cdot 7 ; 9 \cdot 1(2) \\
6 \cdot 9 \pm 1 \cdot 3(13) \\
5 \cdot 2-8 \cdot 7\end{array}$ & $\begin{array}{l}30 \pm 10(17) \dagger \\
9-48 \\
40 \pm 14(5) 8 \\
24-56 \\
42 \pm 17(26) \\
15-67\end{array}$ \\
\hline
\end{tabular}

Significantly different from control value: $\ddagger=p<0.001, \dagger=p<0.01$, (Student's $t$ test).

$\S$ Excluding group $\mathrm{F}$ patient ( $4 \mathrm{ng} \mathrm{HVA} / \mathrm{ml})$. Control HVA value is from Palmer et al. ${ }^{14}$

$\mathrm{SD}=$ standard deviation. 
Table 4 Individual patient details

\begin{tabular}{|c|c|c|c|c|c|c|}
\hline Group & Patient & Age (yr) & Sex & $\begin{array}{l}\text { Duration } \\
\text { of illness } \\
\text { (years) }\end{array}$ & $\begin{array}{l}\text { Family } \\
\text { history }\end{array}$ & $\begin{array}{l}\text { Psychiatric } \\
\text { history }\end{array}$ \\
\hline$\underset{G}{F}$ & $\begin{array}{c}\text { disease } \\
19 \\
20 \\
21 \\
22 \\
23 \\
24\end{array}$ & $\begin{array}{l}57 \\
51 \\
50 \\
53 \\
43 \\
66\end{array}$ & $\begin{array}{l}\mathbf{M} \\
\mathbf{F} \\
\mathbf{M} \\
\mathbf{F} \\
\mathbf{M} \\
\mathbf{F}\end{array}$ & $\begin{array}{l}3 \\
4 \\
3 \\
7 \\
6 \\
2\end{array}$ & $\begin{array}{l}- \\
+ \\
+ \\
- \\
+ \\
+\end{array}$ & $\begin{array}{l}- \\
\overline{+} \\
\overline{+} \\
-\end{array}$ \\
\hline
\end{tabular}

+ denotes presence; - denotes absence.

the cerebral cortex. Patients in groups $\mathrm{E}$ and $\mathrm{F}$ had normal electroencephalograms, whereas the group $G$ patient showed a non-specific diffuse increase in theta and delta wave activity similar to that found in Alzheimer's disease patients. Values for HVA in the CSF were comparable to control values, except in the group $\mathrm{F}$ patient who had profoundly low levels. Individual patient details are shown in table 4.

\section{Alzheimer's disease patients}

Despite sharing the same pathological and chemical characteristics, patients with Alzheimer's disease did not present a uniform psychological syndrome. Examination of patients distinguished four clinical profiles, groups A-D.

Group A: Eleven patients formed the largest single group, and exhibited a picture of language disorder and amnesia, together with perceptuospatial abnormalities, leading to executive difficulties. In all, loss of memory was reported as an early symptom. In addition patients had become lost in their surroundings, misaligned utensils, had difficulty dressing and failed to recognise objects and faces, suggesting the presence of visuo-spatial disorder. Some patients had on occasions conversed with their own reflection in a mirror, and had believed individuals on a television screen to be present in the room. Relatives noted also lack of understanding, the use of incorrect words in speech, an apparent loss of interest in reading, and, to the relatives' surprise, an inability of the patient to write his signature. Language disorder was regarded as a late symptom in most patients, but was the presenting feature in one patient. Reports of increased anxiety and loss of confidence were common. However, there was no history of gross social misconduct and abnormal behaviour was generally explicable in? terms of the patient's cognitive abnormality. Relatives tended to regard the patient's personality as fundamentally unchanged.

On mental examination, speech was essentially fluent, although spontaneous output was reduced and in two severely affected patients limited to monosyllables and stereotyped utterances. Occassional literal paraphasic errors were noted. One patient had a stammering, palilalic speech. There was some word finding difficulty. A reduction in memory span appeared to compromise performance on tests of comprehension. In addition patients had particular difficulty understanding phrases and sentences involving complex grammatical relationships, evident both on tests of aural and reading comprehension.

Difficulty locating objects and body parts suggested a spatial disorder, and in view of loss of spatial configuration in drawings and block constructions, this appeared to be a major factor affecting performance on constructional tasks, overriding executive difficulties (table 5 ). In reading, patients 
Table 5 Profiles of psychological disorder

\begin{tabular}{|c|c|c|c|c|c|c|}
\hline & & Language & Perceptuo-spatial & Executive & Memory & Social conduct \\
\hline \multicolumn{7}{|c|}{ Alzheimer's disease } \\
\hline A & 1 & + & ++ & + & + & - \\
\hline & 2 & + & ++ & + & + & - \\
\hline & 3 & + & ++ & + & + & - \\
\hline & 4 & + & ++ & + & + & - \\
\hline & 5 & + & ++ & + & + & - \\
\hline & 6 & + & + & + & + & - \\
\hline & 7 & + & + & + & + & - \\
\hline & 8 & + & ++ & + & + & - \\
\hline & 9 & + & ++ & + & + & - \\
\hline & 10 & + & + & - & ++ & - \\
\hline & 11 & + & + & - & + & - \\
\hline \multirow[t]{3}{*}{ B } & 12 & - & + & - & ++ & - \\
\hline & 13 & - & + & - & ++ & - \\
\hline & 14 & - & ++ & - & + & - \\
\hline \multirow[t]{2}{*}{ C } & 15 & - & + & ++ & + & - \\
\hline & 16 & - & + & ++ & + & - \\
\hline \multirow[t]{2}{*}{ D } & 17 & - & - & - & ++ & - \\
\hline & 18 & - & - & - & ++ & - \\
\hline \multicolumn{7}{|c|}{ Non-Alzheimer's disease } \\
\hline & 19 & - & - & - & + & ++ \\
\hline & 20 & - & - & - & + & ++ \\
\hline & 21 & - & - & - & + & ++ \\
\hline & 22 & - & - & - & + & ++ \\
\hline $\mathbf{F}$ & 23 & + & + & ++ & + & - \\
\hline G & 24 & + & ++ & + & + & - \\
\hline
\end{tabular}

$+=$ abnormality observed; $-=$ abnormality not observed.

$++=$ abnormality most prominent (this refers to the characteristic most clinically obtrusive in the individual patient's performance, and does not indicate severity relative to other patients).

had difficulty tracking along a line. Perceptual failure in identifying objects and faces occurred in a minority of patients, but was less common than spatial abnormalities. In the manipulation of objects errors appeared to relate predominantly to spatial rather than executive difficulty: a pen would be held upside down; in writing, strokes could be produced but the spatial relationship between strokes was inaccurate. Simple motor rhythms could be reproduced except where this exceeded the patient's memory span. In no patient was there a disturbance of gait. All patients demonstrated poor visual and verbal memory assessed by both recall and recognition, and impaired immediate recall of a seven item name and address. All were disorientated for time and place and had defective knowledge of contemporary and past events.

During examination patients displayed socially preserved behaviour. Overt signs of anxiety were common when confronted with difficult tasks, suggesting some degree of awareness of their own difficulties.

Consistent with the observation of language and perceptuo-spatial disabilities scores on both the Verbal and Performance scales of the WAIS were significantly reduced, and in some patients formal assessment was not possible (table 6). Clinical ratings were of severe impairment.

In contrast to striking cognitive impairment physical signs were few and of mild degree. On neurologi- cal examination there were the findings of akinesia, rigidity, expressionless facies, brisk tendon reflexes and extensor plantar responses in a proportion of

Table 6 Clinical ratings and WAIS scores

\begin{tabular}{|c|c|c|c|c|}
\hline & & \multirow[t]{2}{*}{$C R$} & \multicolumn{2}{|l|}{ WAIS } \\
\hline & & & Verbal IQ & Performance IQ \\
\hline \multicolumn{5}{|c|}{ Alzheimer's disease } \\
\hline \multirow[t]{11}{*}{ A } & 1 & 6 & 68 & 63 \\
\hline & 2 & 7 & 70 & 52 \\
\hline & 3 & 7 & 58 & 54 \\
\hline & 4 & 9 & nt & nt \\
\hline & 5 & 7 & 81 & nt \\
\hline & 6 & 6 & nt & nt \\
\hline & 7 & 4 & 77 & 53 \\
\hline & 8 & 8 & nt & nt \\
\hline & 9 & 6 & 65 & 50 \\
\hline & 10 & 6 & 56 & 59 \\
\hline & 11 & 5 & - & - \\
\hline \multirow[t]{3}{*}{ B } & 12 & 5 & 65 & nt \\
\hline & 13 & 4 & 96 & 73 \\
\hline & 14 & 5 & 83 & 53 \\
\hline \multirow[t]{2}{*}{ C } & 15 & 7 & 81 & nt \\
\hline & 16 & 7 & - & - \\
\hline \multirow[t]{2}{*}{ D } & 17 & 2 & 123 & 99 \\
\hline & 18 & 2 & 97 & 95 \\
\hline \multicolumn{5}{|c|}{ Non-Alzheimer's disease } \\
\hline \multirow[t]{4}{*}{$E$} & 19 & 1 & 93 & 106 \\
\hline & 20 & 2 & 90 & 76 \\
\hline & 21 & 1 & 92 & 82 \\
\hline & 22 & 2 & nt & nt \\
\hline $\mathbf{F}$ & 23 & 6 & 68 & 55 \\
\hline $\mathbf{G}$ & 24 & 9 & nt & nt \\
\hline
\end{tabular}

$\mathbf{C R}=$ clinical rating; control rating $=\mathbf{0}$.

$\mathrm{nt}=$ not formally testable.

$\underline{\mathrm{nt}}=\mathbf{\text { not formally testable. }}$ 
Table 7 Neurological motor signs

\begin{tabular}{|c|c|c|c|c|c|c|c|c|}
\hline Group & $\begin{array}{l}\text { No in } \\
\text { group }\end{array}$ & $\begin{array}{l}\text { Express. } \\
\text { facies }\end{array}$ & Akinesia & $\underset{\text { rigidity }}{\text { Limb }}$ & $\begin{array}{l}\text { Hyper- } \\
\text { reflexia }\end{array}$ & $\begin{array}{l}\text { Extensor } \\
\text { plantar }\end{array}$ & Myoclonus & $\begin{array}{l}\text { Grasp } \\
\text { reflex }\end{array}$ \\
\hline \multicolumn{9}{|c|}{ Alzheimer's disease } \\
\hline B & 3 & - & - & - & $+(3)$ & - & - & - \\
\hline C & 2 & $+(1)$ & $+(2)$ & $+(2)$ & $+(2)$ & - & $+(1)$ & - \\
\hline \multicolumn{9}{|c|}{ Non-Alzheimer's disease } \\
\hline $\mathbf{F}$ & 1 & + & + & + & + & - & - & - \\
\hline $\mathbf{G}$ & 1 & - & - & - & - & - & - & - \\
\hline
\end{tabular}

Abbreviations: express. facies = expressionless facies.

+ denotes abnormality present; - denotes abnormality absent; ( ) denotes number of patients affected.

patients (table 7). Muscular power was normal. Elementary sensation was preserved, whereas sensory tasks incorporating a spatial element, such as visual and tactile localisation and postural awareness were failed (table 8 ).

Group B: Three female patients demonstrated a pattern of psychological impairment similar to that of group A patients, with the exception that no linguistic disturbance was reported by relatives, or was evident on testing. Despite memory loss these patients had a normal digit span. WAIS scores revealed a discrepancy between Verbal and Performance IQ in two patients (table 6). Neurological signs were limited to brisk reflexes (table 7), and in one patient defective postural sense (table 8).

Group C: Two male patients differed from groups $A$ and $B$ in that their prominent and presenting disability was a profound loss of motor skills. They were unable to handle cutlery, manipulate tools, shave or dress. Their gait was shuffling, and they were unable to climb in and out of a bed or motor car. A deterioration in their memory, and a change in the quality of voice had also been noted, although these symptoms were regarded as trivial in comparison to the patients' profound "physical" problems. The patients' personality was regarded as unchanged, and social and personal limitations were thought consistent with their physical disabilities.

On testing, spontaneous speech lacked prosody, and there was a mild dysarthria. However, speech was grammatically correct and contained no paraphasic errors. There was no evidence of disorder of comprehension, repetition or word finding, although responses to metaphor and proverb were concrete in one patient. Simple mental and written calculations were failed. There was difficulty identifying lines, drawings and faces and in the interpretation of thematic pictorial scenes. Location of points on a map was impaired. In reading there was some difficulty tracking along a line.

All tasks involving manual responses were carried out abnormally. Neither patient was able to gesture symbolically, or orientate his limbs to copy or command. In writing and drawing, there was difficulty in initiating the appropriate actions, and once initiated perseverative strokes were common. In constructional tasks the patients had difficulty manipulating blocks or matchsticks, there was loss of spatial configuration in their responses and a tendency to build on top of the original. Sequential, rhythmical and alternating hand movements were impaired, and perseverative responses were frequent, in con-

Table 8 Neurological sensory signs

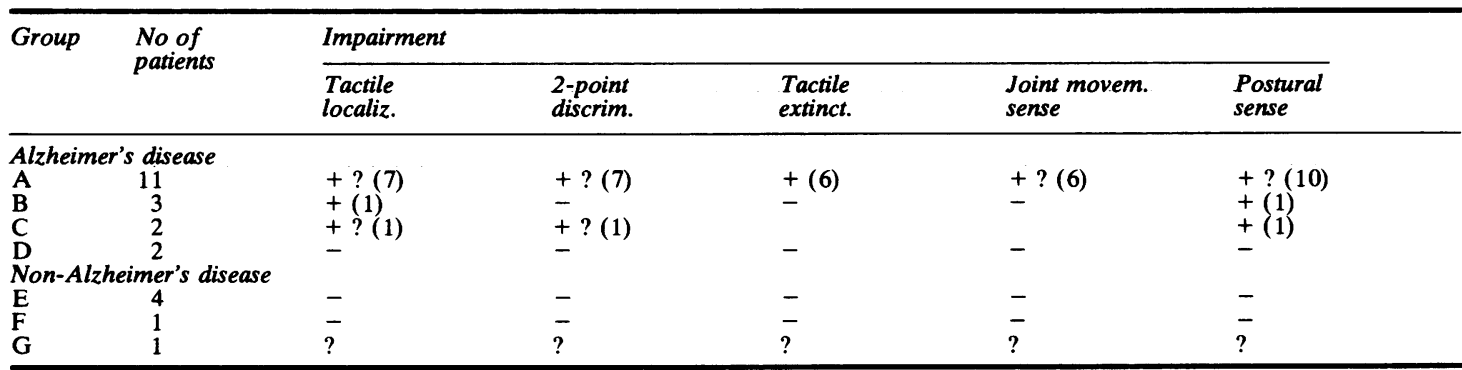

+ denotes presence of impairment; - denotes absence of impairment; ? denotes that interpretation of findings was uncertain since the patient's ability to cooperate was compromised by cognitive disorder; ( ) indicates number of patients affected.

Abreviations: tactile localiz. = tactile localization; 2-point discrim. = 2-point discrimination; tactile extinct. = tactile extinction on left $(\mathrm{L})$ or right (R); joint movem. sense = sense of joint movement. 
trast to the performance of group A and B patients in which perseverations of motor actions were absent. Both patients failed on immediate and delayed recall and learning tasks, and had defective general knowledge. One patient was disoriented in time and place. Both patients displayed appropriate social behaviour and, although they tended to underemphasise their problems, they retained some awareness of their disability. WAIS scores are available only on one patient, who showed a significant discrepancy between performance on Verbal and Performance items (table 6). Neurological examination revealed in both patients expressionless facies, an inability to protrude the tongue, mild akinesia, moderate muscular rigidity and brisk tendon reflexes (table 7). Elementary sensory testing was intact, but severe impairment of all complex purposive movement of the upper limbs prevented interpretation of postural and localising abilities (table 8). Gait was slow, lacking normal steppage, the patients shuffling in continuous contact with the floor. One patient, in addition to a lack of initiation and fragmentation of arm movements, exhibited myoclonic jerks during action. Neither patient was incontinent.

Computed tomography revealed strikingly enlarged cerebral ventricles in both patients in comparison with patients in other groups. The cortical subarachnoid spaces were also enlarged. Because of the profound gait disorder and amnesia together with the radiological signs of considerable hydrocephalus, a dynamic metrizamide cisternogram was carried out to exclude communicating hydrocephalus, the results of which were inconclusive. Group D: Two men exhibited a selective amnesia. They presented with a prolonged history of progressive memory failure. No other cognitive difficulties had been noted by relatives and the patients' character and social conduct were regarded as unchanged, apart from some increased apathy and loss of intiative. In both, memory difficulties led to reduced occupational efficiency, resulting in one patient, a teacher, seeking early retirement. The other, however, retained his job as a printer for two years following investigation and travelled to work independently.

Mental testing revealed no evidence of perceptuo-spatial or linguistic disorder, loss of manual skills or gait abnormality. Both patients could read, write, spell, calculate, could carry out constructional tasks, and had normal powers of abstraction. Both patients had a normal digit span, and had accurate immediate recall of a seven item name and address. However, neither patient could recall any information from the name and address after a two minute delay, failed to benefit from provision of multiple-choice alternatives, and showed no signs of familiarity when the name and address was represented. Performance on a two choice picture recognition task approached floor level. The patients' amnesia, demonstrated for both visual and verbal material, was of a degree comparable to or on occasions more severe than that of other Alzheimer's disease patients. Knowledge of celebrities whose fame preceded the presumed onset of amnesia was superior to knowledge of contemporary figures. General knowledge of current events was impaired. Both patients on interview displayed preserved social behaviour and were fully cooperative. There was no suggestion of increased distractibility or inattention. Both patients admitted to poor memory but appeared not to appreciate the extent of the disorder, and showed no evidence of anxiety.

On the WAIS, a discrepancy between Verbal and Performance IQ observed in one patient (table 6), was attributed to poor performance on the Digit Symbol sub-test. In the other patient, current IQ was not statistically different from his premorbid level of functioning, estimated by the Schonell graded word reading test. ${ }^{15}$ Neurological examination was normal.

\section{Non-Alzheimer's disease patients}

Group E: The prominent feature in these four patients was a change in personality and social conduct (table 5). Two men had been dismissed from their jobs for incompetence. Two females had failed to manage their household affairs and one had begun shoplifting openly without moral qualms. The other, after a number of depressive illnesses, which had responded to medical and electroconvulsive therapy, had, following a gynaecological procedure, become hypochrondriacally obsessed with perineal symptoms. All four patients had shown loss of interest in personal grooming, hygiene and table manners. Social behaviour was characterised by inappropriate jocularity, disinhibition, rudeness and a lack of sympathy for and empathy with others. They showed no concern for the future, took no initiative, were inattentive to their surroundings and denied the changes in character observed in them by others. Relatives also commented on a variable forgetfulness.

On mental examination it was difficult to engage patients in testing and they showed signs of restlessness and impatience. Responses to tasks were of two forms: either superficial with little concern for accurracy, or slow, laboured and perseverative. Language functions were generally intact. However, a mild word finding difficulty in naming object parts to confrontation was noted in three patients, and metaphors and proverbs were interpreted literally. 
In drawing and constructional tasks errors occurred in the form of omission of detail. Since constructions were executed effortlessly, and showed appropriate spatial relationships these errors were interpreted as secondary to the patients' desultory approach and reflecting inattention to detail. There was no evidence of perceptuo-spatial impairment or loss of manual skills. However, picture sequencing and block sorting performance was poor, and suggested impaired abstraction and mental flexibility. Memory testing revealed variable erratic performance. A normal digit span was attained on some occasions, but not others. Delayed recall and recognition performance was variable and on recall tasks confabulatory responses were noted.

WAIS scores were not grossly abnormal, although formal assessment was impossible in one patient owing to inattention and lack of sustained cooperation (table 6). The low Performance score in one patient reflected a particularly poor performance on the picture arrangement subtest. On neurological examination the abnormal signs were confined to the presence of extensor plantar responses in two patients (table 7) and a grasp reflex in two patients. There was no evidence of akinesia or rigidity.

Group F: One male patient had a history of declining memory, and increasingly indecipherable speech and script. He was however able to dress himself, could locate objects in the environment, and was regarded by relatives as being able to understand spoken and written language. There was no account of gross social misconduct or personality change, although he was reported to be more verbally aggressive and irritable than formerly. His personal hygiene and grooming were acceptable.

Mental examination revealed a picture predominantly of memory and praxic difficulties. His spontaneous speech was linguistically correct, but lacked prosody, was slightly dysarthric and frequently became hesitant, stammering and palilalic. Simple aural and written comprehension, and word finding were intact, but interpretation of complex utterances and metaphor and proverb was concrete, and repetition was limited. He could not perform simple mental and written calculations. Perceptual identification of objects, drawings and faces was intact, and he could interpret pictorial scenes, locate towns on a map, and could track along a line. Responses were effortless and occasionally impulsive. In contrast, he had substantial difficulty carrying out tasks involving manual skills, such as drawing, block constructions, and production of sequential, rhythmical and alternating hand movements. Script was sufficiently indecipherable to prevent assessment of linguistic content. Performance on motor and constructional tasks was slow, and responses were perseverative. On memory testing his immediate and delayed recall of information and general knowledge were defective. He was however oriented in time and place. During testing he was courteous and well-mannered, and expressed anxiety suggesting some awareness of his difficulties.

The WAIS revealed impaired performance on both the Verbal and Performance scales (table 6). On neurological examination he had an expressionless facies, akinesia, muscular rigidity of the limbs and very brisk tendon reflexes (table 7). Elementary sensation and coordination were intact (table 8) but he had mild postural difficulties in imitating the examiner's hand positions.

Group G: One female patient had developed over one year impaired memory, difficulties in recognising objects and individuals, and in dressing. She had frequently become lost. In addition relatives regarded her speech as incomprehensible, and noted her inability to read, write or calculate. Social misconduct was not reported. She had become tranquil and apathetic with occasional outbursts of irritability, anxiety and weeping.

Mental examination revealed the presence of language disorder, perceptuo-spatial difficulties and amnesia. Her spontaneous speech was fluent although output was reduced and lacking in substantives. There was a severe impairment of both aural and written comprehension and in repetition and word finding. Paraphasic errors were noted. She could not read, write or calculate. Disorders of linguistic comprehension and expression clearly compromised her performance on perceptual and spatial tasks, although errors could not be explained exclusively in these terms. She displayed difficulties in perceptual matching, visual tracking, spatial location and other tasks making few linguistic demands. Moreover, her drawings and constructions demonstrated severe loss of spatial configuration. She appeared to have little memory for individuals or for day to day incidents. Formal memory assessment was however precluded by her perceptuo-spatial and language disorders. Behaviour during examination was socially appropriate. She displayed signs of anxiety and distress when confronted with tasks beyond her capabilities.

She was formally untestable on the WAIS. There were no signs of akinesia or rigidity, and tendon reflexes were normal. Postural sense and tactile localisation were defective.

\section{Progression}

The time that has elapsed since initial investigation of patients ranges from 1-5 years, mean 3 years. With progression of the disease some of the clinical differences between groups have become eroded. Of 
patients with Alzheimer's disease those in group B have become aphasic and their clinical picture resembles that of group A. Both group A and B patients have developed increasing difficulty carrying out manual tasks in common with group C. In these Alzheimer's disease patients palilalia has become an increasingly common characteristic of speech resembling that of the non-Alzheimer's disease group F patient. Signs of increasing muscular rigidity and akinesia have become increasingly apparent in Alzheimer's disease patients in groups $\mathrm{A}, \mathrm{B}$ and $\mathrm{C}$.

The two group D patients with Alzheimer's disease by contrast retained a selective amnesia respectively for 3 and 4 years, their duration of illness spanning a total of 8 and 10 years. Minor visuospatial difficulties are now beginning to emerge in both patients.

The four non-Alzheimer's disease patients in group $\mathrm{E}$ have shown a further deterioration in social behaviour, but no evidence or perceptuo-spatial disorder or aphasia has emerged.

The group $F$ patient became more withdrawn and inactive, speech became unintelligible and comprehension impaired, preventing formal psychological assessment. He displayed profound muscular rigidity, akinesia and a flexed posture. He died 3 years following investigation, and necropsy revealed severe degeneration of the corpus striatum together with generalised cerebral atrophy. No senile plaques or neurofibrillary tangles were observed in the cerebral cortex.

The group $G$ patient retains a picture of severe amnesia, perceptuo-spatial disorder and aphasia, in the absence of extra-pyramidal features on neurological examination. She is formally untestable.

\section{Discussion}

The present findings support the suggestion that the cerebral atrophies represent a pathologically heterogeneous group of conditions. Consistent with other studies ${ }^{216}$ Alzheimer's disease accounted for the largest proportion of patients $(75 \%)$. In keeping with other reports of specific chemical abnormalities in Alzheimer's disease 17-20 $^{17}$ patients with Alzheimer's disease in the present series showed a reduction in cholinergic activity. However, six patients $(25 \%)$ showed no specific pathology, and an absence of the chemical changes associated with Alzheimer's disease. It is unlikely that these six cases represent false negative examples of Alzheimer's disease resulting from sampling bias at biopsy. Tissue was obtained from cortical sites at which Alzheimer's disease changes are known to be particularly profuse. ${ }^{21}$ Moreover, psychological disorder was sufficiently marked that pathological change would have been expected to be readily evident. Furthermore, in one case (group F) the absence of Alzheimer's disease changes was confirmed at subsequent necropsy. The 24 patients reported here appear to be representative of the spectrum of patients with presenile dementia investigated in the neurological unit in terms of the nature and degree of psychological disorder.

Mental testing showed that patients did not display a global and undifferentiable psychological impairment. Rather, distinctive patterns emerged, shared by a number of patients, allowing clinical grouping. Certain clinical findings would appear to be of diagnostic significance. All Alzheimer's disease patients displayed a progressive cognitive deterioration in the presence of relative preservation of conduct and social behaviour. All had an abnormal EEG. In contrast, in the largest group of non-Alzheimer's disease patients (group E) the predominant features were change in character and social conduct. The EEG was normal. Nevertheless, the pathological, chemical and EEG manifestations of cerebral disorder could not be predicted with complete accuracy on the basis of pattern of psychological disorder. The presence of amnesia together with focal cortical features, such as aphasia, apraxia and agnosia has been described as characteristic of Alzheimer's disease. ${ }^{322}{ }^{23}$ In the present series these features, while prevalent among Alzheimer's disease patients did not define Alzheimer's disease patients exclusively. Patterns of disorder found in Alzheimer's disease patients were shared by two non-Alzheimer's disease patients categorised as groups $F$ and $G$.

Amongst Alzheimer's disease patients distinct cognitive profiles could be identified. Clearly, the fact that patients were examined at different times during the course of disease contributes to the observed distinctions. For example, the group B patients who were free from language disorder on initial investigation later became undifferentiable from group A patients. Group A and B patients who were initially free from manual difficulties later experienced executive difficulties similar to those of group C patients. Nevertheless, the identification of clinical distinctions does suggest that the pattern or cognitive decline may not be entirely uniform in Alzheimer's disease patients and the temporal course may itself differ. For example, in group C patients manual and gait difficulties were pronounced early in the course of the disease and predominated over other symptoms, yet in other patients such difficulties were a relatively late development. Memory disorder, which in many 
patients was rapidly accompanied by other cognitive deficits, in two patients (group D) remained the sole symptom for almost a decade. Time of onset of disease is of course difficult to specify with accuracy. Yet, error associated with identifying the beginning of symptoms could not account for the substantial discrepancies in temporal progression observed in the present series of Alzheimer's disease patients.

Clinical sub-groups of Alzheimer's disease may present particular diagnostic problems. In patients presenting a predominantly apraxic syndrome in the presence of markedly dilated cerebral ventricles, the potentially treatable disorder of normotensive hydrocephalus must be an alternative diagnosis. Difficulties in distinguishing the two conditions has been described elsewhere. ${ }^{3}$ In the present series the absence of early incontinence despite gross apraxia and amnesia in the two group $C$ patients favoured the diagnosis of cerebral atrophy.

In the two group $D$ patients, the isolated disorder of long-term memory, with intact immediate memory span, bears some resemblance to the classical Wernicke-Korsakoff amnesic syndrome in which the predominant pathological lesions lie in the limbic system. ${ }^{24}$ If either patient had abused alcohol then an alcoholic encephalopathy might have been assumed. Pathological reports have suggested that limbic structures may be particularly affected in Alzheimer's disease. ${ }^{25} 26$ It may be that in some instances of Alzheimer's disease the pathological process remains more densely regionalised in the brain than in other cases. Topographical selectivity is supported by reports of Alzheimer's disease presenting as focal lesions. ${ }^{27} 28$ It is of diagnostic and therapeutic relevance that the group D patients, on the basis of temporal progression of disease, would not have fulfilled the criteria for Alzheimer's disease outlined by others, ${ }^{232930}$ and on clinical grounds would therefore have been excluded from a therapeutic trial. Yet, it is such patients with relatively circumscribed deficits who might be expected to show most benefit from rational therapies.

It might be expected that, despite initial diversity in psychological disorder, the end stages of Alzheimer's disease would be sufficiently clinically uniform to reduce diagnostic uncertainty. Yet, early diagnosis is essential if rational therapies are to be administered. Moreover, in advanced stages of disease patients become formally untestable. Differences between Alzheimer's disease and nonAlzheimer's disease therefore become submerged since it becomes no longer possible to infer the relevant factors underlying the patient's disability. Critical distinctions between forms of dementia are most likely to be apparent early in the course, exemplified in this study by the sharp contrast in clinical picture between Alzheimer's disease patients and those non-Alzheimer's disease patients referred to as group $\mathrm{E}$.

The disorder in group $\mathrm{E}$ patients was characterised by loss of social awareness, disinhibition, forgetfulness and distractibility. Language and perceptuo-spatial functions were essentially preserved, although a mild anomia was apparent. Given the pattern of psychological disability one might suspect fronto-temporal areas to be predominantly affected, raising the possibility of a diagnosis of Pick's disease. ${ }^{31}$ The normal EEG and positive family history in two patients would support this diagnosis. Unfortunately, conventional computed tomography failed to differentiate between atrophic changes in these and Alzheimer's disease patients, and no specific pathological lesion was seen akin to that found in necropsy studies of Pick's disease. ${ }^{32}$ Precise diagnosis therefore remains open. Nevertheless, the possibility of this diagnosis is itself, of interest, since it would account for four of the 24 patients (17\%). Pick's disease is generally believed to be extremely rare, and on this belief clinical studies of presenile dementia may make no attempt to distinguish Pick's disease from Alzheimer's disease. ${ }^{33}$ If the present patient sample is, as anticipated, representative of the population of patients with primary degenerative presenile dementia, then the incidence of this non-Alzheimer's disease form of cerebral atrophy may be more common than is generally recognised.

The group $\mathrm{F}$ patient is intriguing in that he displays a clinical picture similar to Alzheimer's disease patients and yet the absence of histological hallmarks of Alzheimer's disease has been confirmed at necropsy. There were some "atypical" clinical features: he was considerably younger than other patients studied and the EEG was reported as normal. Nevertheless, Alzheimer's disease has been reported to occur in patients as young as 16 years. ${ }^{34}$ Repeated EEGs were not obtained so that a continued normal recording with advanced dementia cannot be inferred. Moreover, even retrospectively, no clear psychological distinctions could be defined to distinguish this patient from those with Alzheimer's disease. Necropsy revealed a distribution of lesions in the striatum compatible with a marked reduction of the dopamine metabolite HVA in the cerebrospinal fluid.

The group $G$ patient appears patho-chemically distinct from other patients, yet the profound amnesia, perceptual, spatial and language disorder could not readily be distinguished from that found in Alzheimer's disease patients. It may be of diagnostic significance however that despite severe and rapidly progressive psychological impairment she remained 
free of the akinesia and rigidity common to advanced forms of Alzheimer's disease. Further neurochemical examination of tissue and CSF might provide further differential information in this and other non-Alzheimer's disease patients.

Both patients in groups $F$ and $G$ and two of the four group $E$ patients had a positive family history of dementia: $67 \%$ of the non-Alzheimer's disease patients. While familial dementia was seen also in Alzheimer's disease patients this was relatively uncommon: 3 patients, $17 \%$. The relatively greater incidence of familial cases in non-Alzheimer's disease compared to Alzheimer's disease has been reported by others. ${ }^{2} 30$

All Alzheimer's disease patients had an abnormal EEG, while in non-Alzheimer's disease patients the EEG was normal in all but one case. The relevance of EEG findings in distinguishing Alzheimer's disease from non-Alzheimer's disease has been reported elsewhere..$^{35-37}$

The present findings confirm that some clinical distinctions can be drawn between patients with presenile dementia which may assist in diagnosis. It would seem that the presence of amnesia, perceptuo-spatial disorder and aphasia, evolving generally in that order and in the absence of breakdown in social competence and associated with an abnormal EEG strongly suggests a diagnosis of Alzheimer's disease. A contrasting picture of social breakdown without the focal cortical features of aphasia, apraxia and agnosia, together with a normal EEG raises the possibility of non-Alzheimer's disease, for example, Pick's disease. Nevertheless, the findings also illustrate heterogeneity of presentation and course of Alzheimer's disease. Clinical patterns similar to those found in Alzheimer's disease patients occur also in non-Alzheimer's disease patients, highlighting the difficulty of making a definitive diagnosis solely on clinical grounds. While refinements in psychological investigations and the development of new neuroradiological imaging techniques may improve clinical diagnosis during life, only by relating clinical data to neuropathological and chemical characteristics of cerebral tissue can the nosological classification of primary cerebral atrophy be achieved.

We thank Dr CCT Smith for CAT determinations, Drs J Kincey and M Vaughan for WAIS administration, and Professor J Dobbing for providing laboratory facilities. We are grateful for financial support to the Medical Research Council, the Brain Research Trust, the Miriam Marks Charitable Trust and the North West Regional Health Authority.
References

' Marsden CD, Harrison MJG. Outcome of investigation of patients with presenile dementia. $\mathrm{Br}$ Med J 1972;2:249-52.

${ }^{2}$ Sim M, Turner E, Smith WT. Cerebral biopsy in the investigation of presenile dementia. 1. Clinical aspects. Br J Psychiatry 1966;112:119-25.

${ }^{3}$ Coblentz JM, Mattis S, Zingesser LH, Kasoff SS, Wisniewski HM, Katzman R. Presenile dementia. Clinical aspects and evaluation of cerebrospinal fluid dynamics. Arch Neurol 1973;29:299-308.

4 Benton JS, Bowen DM, Allen SJ, et al. Alzheimer's disease as a disorder of the isodendritic core. Lancet $1982 ; 1: 456$.

${ }^{5}$ Cummings JL, Benson DF. Subcortical dementia. Review of an emerging concept. Arch Neurol 1984;41:874-9.

${ }^{6}$ Neary D, Snowden JS, Mann DMA, et al. Alzheimer's disease: a correlative study. J Neurol Neurosurg Psychiatry 1986; 49:(in press)

${ }^{7}$ Aherne WA, Diggle PJ. The estimation of neuronal population density by a robust distance method. $J$ Microscopy 1978;114:285-93.

${ }^{8}$ Mann DMA, Neary D, Yates PO, Lincoln J, Snowden JS, Stanworth P. Neurofibrillary pathology and protein synthetic capability in nerve cells in Alzheimer's disease. J Neuropathol Appl Neurobiol 1981;7:37-47.

${ }^{9}$ Sims NR, Bowen DM, Davison AN. ${ }^{14} \mathrm{C}$-acetylcholine synthesis and ${ }^{14} \mathrm{C}$-carbon dioxide production from $\mathrm{U}-{ }^{14} \mathrm{C}$ glucose by tissue prisms from human neocortex. Biochemic J 1981;196:867-76.

${ }^{10}$ Fonnum F. A rapid radiochemical method for the determination of choline acetyltransferase activity. $J$ Neurochem 1975;24:407-9.

" Bowen DM, Benton JS, Spillane JA, Smith CCT, Allen SJ. Choline acetyltransferase activity and histopathology of frontal neocortex from biopsies of demented patients. J Neurol Sci 1982;57:191-202.

12 Sullivan PA, Munaghan D, Callaghan N, Kantamenani BD, Curzon G. Cerebral transmitter precursors and metabolites in advanced neural disease. $J$ Neurol Neurosurg Psychiatry 1978;41:581-8.

${ }^{13}$ Curzon G, Kantamenani BD, Tricklebank MD. A comparison of an improved o-phthalaldehyde fluorometric method and high pressure liquid chromatography in the determination of brain 5 hydroxyindoles of rats treated with 1-tryptophan and p-chlorophenyl alanine. Br J Pharmacol 1981;73:555-61.

14 Palmer AM, Sims NR, Bowen DM, et al. Monamine metabolite concentrations in lumbar cerebrospinal fluid of patients with histologically verified Alzheimer's dementia.J Neurol Neurosurg Psychiatry 1984;47:481-4.

is Nelson HE, McKenna P. The use of current reading ability in the assessment of dementia. $\mathrm{Br} \mathrm{J}$ Social Clin Psychol 1975; 14:259-67.

${ }^{16}$ Bowen DM, Sims NR, Benton S, Haan EA, Smith CCT, Neary D, Thomas DJ, Davison AN. Biochemical changes in cortical brain biopsies from demented patients in relation to morphological findings and pathogenesis. In: Corkin S, ed. Alzheimer's Disease: $a$ 
Report of Progress. (Aging, volume 19). New York: Raven Pres, 1982:1-8.

${ }^{17}$ Bowen DM, Smith CB, White P, Davison AN. Neutrotransmitter-related enzymes and indices of hypoxia in senile dementia and other abiotrophies. Brain 1976;99:459-96.

${ }^{18}$ Davies P, Maloney AJF. Selective loss of central cholinergic neurones in Alzheimer's disease. Lancet 1976;2: 1403.

${ }^{14}$ Perry EK, Perry RH, Blessed G, Tomlinson BE. Necropsy evidence of central cholinergic deficits in senile dementia. Lancet 1977;1:189.

${ }^{20}$ Rossor MN, Fahrenkrug J, Emson P, Mountjoy C, Iversen L, Roth M. Reduced cortical choline acetyltransferase activity in senile dementia of Alzheimer type is not accompanied by changes in vaso-active intestinal polypeptide. Brain Res 1980;201:249-53.

${ }^{21}$ Wilcock GK, Esiri MM. Plaques, tangles and dementia. A quantitative study. J Neurol Sci 1982;56:343-56.

${ }^{22}$ Alzheimer A. Uber eine eigenartige Erkrankung der Hirnrinde. Allgemeine Zeitschrift fur Psychiatrisch und Psychisch-Gerichtlich Medizin 1907;64:146. Translated by Wilkins RH, Brody IA. Arch Neurol 1969;21:109.

${ }^{23}$ Sjogren T, Sjogren H, Lindgren GH. Morbus Alzheimer and morbus Pick. Acta Psychiatr Neurol Scand 1952;suppl.82:9-152.

${ }^{24}$ Victor M, Adams RD. Collins GH. The WernickeKorsakoff syndrome. Oxford: Blackwell Scientific Publications, 1971.

${ }^{25}$ Brun A, Gustafson L. Distribution of cerebral degeneration in Alzheimer's disease. A clinico-pathological study. Arch Psychiatr Nervenkr 1976;223:15-33.

${ }^{26}$ Brun A, Englund E. Regional pattern of degeneration of Alzheimer's disease: neuronal loss and histopatholog- ical grading. Histopathology 1981;5:549-64.

${ }^{27}$ Crystal HA, Horoupian DS, Katzman R, Jotkowitz S. Biopsy-proved Alzheimer disease presenting as a right parietal lobe syndrome. Ann Neurol 1982;12:186-8.

${ }^{28}$ Podacar S, Williams RS. Alzheimer's disease presenting as slowly progressive aphasia. $R I M e d J$ 1984;67: 181-5.

${ }^{24}$ Gustafson L, Nilsson L. Differential diagnosis of presenile dementia on clinical grounds. Acta Psychiatr Scand 1982;65:194-209.

${ }^{30}$ Sulkava R, Haltia M, Paetau A, Wikstrom J, Palo J. Accuracy of clinical diagnosis in primary degenerative dementia: correlation with neuropathological findings. J Neurol Neurosurg Psychiatry 1983;46:9-13.

${ }^{31}$ Brun A, Gustafson L. Limbic lobe involvement in presenile dementia. Arch Psychiatr Nervenkr 1978;226: 79-93.

${ }^{32}$ Corsellis JAN. Aging and the Dementias. In: Blackwood JW, Corsellis JAN, eds. Greenfield's Neuropathology 1976:796-848.

${ }^{33}$ Seltzer B, Sherwin I. A comparison of clinical features in early- and late-onset primary degenerative dementia. Arch Neurol 1983;40:143-6.

${ }^{34}$ Neumann MA, Cohn R. Incidence of Alzheimer's disease in a large mental hospital. Arch Neurol Psychiatry 1953;69:615-36.

${ }^{35}$ Gordon EB, Sim M. The EEG in presenile dementia. $J$ Neurol Neurosurg Psychiatry 1967;20:285-91.

36 Johannesson G, Brun A, Gustafson L, Ingvar DH. EEG in presenile dementia related to cerebral blood flow and autopsy findings. Acta Neurol Scand 1977;56:89-103.

${ }^{37}$ Johannesson G, Hagberg B, Gustafson L, Ingvar DH. EEG and cognitive impairment in presenile dementia. Acta Neurol Scand 1979;59:225-40. 